\title{
Effect of Duloxetine Acute Treatment against 3, 4 Methylenedioxymethamphetamine-induced Cognitive Impairment and Memory Deficiency in Male Rats
}

\author{
Nasrin Hashemi-Firouzi ${ }^{1}$, Siamak Shahidi ${ }^{*}$ DD, Sara Soleimani-Ast ${ }^{2}$ \\ 1 Neurophysiology Research Center, Hamadan University of Medical Sciences, Hamadan, Iran \\ 2 Anatomy Department, School of Medicine, Hamadan University of Medical Sciences, Hamadan, Iran
}

*Corresponding author:

Siamak Shahidi, Neurophysiology Research Center, Hamadan University of Medical Sciences, Hamadan, Iran Tel: +988118380462337

Email:SiamakShahidi @yahoo.com

Received: 06 Apr. 2020

Accepted: 22 Jun. 2020

ePublished: 01 Aug. 2020

\begin{abstract}
Background and Objective: 3, 4- methylenedioxymethamphetamine (MDMA) is used for recreational purposes worldwide. The use of MDMA resulted in learning and memory dysfunction. Duloxetine, a serotonin/noradrenalin-reuptake inhibitor is also utilized to treat depression and anxiety. The current study aimed to evaluate the effects of duloxetine against MDMA's effect on anxiety, cognition, and memory disturbance in the male rats.

Materials and Methods: Wistar rats received treatment of saline (10 ml $/ \mathrm{kg}$; sham group), "MDMA" (10 mg/kg), "Duloxetine" (10 mg/kg), and Duloxetine plus MDMA (10 mg/kg, each), or no treatment (control) through the intraperitoneal administration for four days. The elevated plus maze (EPM), passive avoidance learning (PAL), Morris water maze (MWM), and novel object recognition (NOR) tests were employed to evaluate the anxiety, memory, and cognition.

Results: The MDMA increased the time spent in open arms in EPM, time spent in the dark part of $\mathrm{PAL}$, and swimming time to reach the platform in MWM. Furthermore, duloxetine inhibited the reduction of the discrimination index, time spent in the dark compartment, and time spent on the platform in NOR, PAL, and MWM tests among rats received MDMA. Moreover, duloxetine decreased time spent in open arms and the target quadrant in EPM and MWM tests.

Conclusion: Our findings suggested that duloxetine treatment attenuated the MDMA-induced anxiolytic response and could improve MDMA-induced cognitive impairment and disturbance in learning and memory.
\end{abstract}

Keywords: Anxiety, 3, 4- Methylenedioxymethamphetamine (MDMA), Learning and memory, Rat

\section{Background}

Ecstasy is regarded as a recreational drug containing 3,4-methylenedioxymethamphetamine (MDMA). Exposure to MDMA produces long-term neurotoxic damage to neurons in the brain [1, 2]; moreover, its administration leads to neurotoxic effects on serotonin (5-HT) neurons [3-5]. The side effects of this drug have been shown to cause physiological changes, such as anxiety, depression, and memory impairment [6-9]. Administration of MDMA to animals induces anxiolytic $[10,11]$ and anxiogeniclike behaviors [12]. The neurodegeneration effects of MDMA exposure can persist for several months after administration [1, 4, 12]. The mention disorders may require psychopharmacological treatment with antidepressant drugs [13]. On the other hand, MDMA has antidepressant-like effects in animals [10].

The antidepressant drugs, such as selective 5-HT reuptake inhibitors and serotonin noradrenaline reuptake inhibitors (SNRIs) attenuated hyperthermia, psychotropic, and cardiovascular responses to
MDMA [14]. Duloxetine (Dlx), a member of the SNRI family, inhibits the reuptake of both serotonin and norepinephrine into presynaptic neurons [15]. It has been shown that the SNRIs can improve anxiety, depression, withdrawal syndrome, and neurodegeneration resulting from methamphetamine and MDMA [16-18].

There are controversial reports about the duloxetine effect in memory. Duloxetine has cognitive improvements in patients with depression [19] and induces positive effects on affective bias test in rats [20]; however, it has no effects on cognition, memory, and consolidation in rodents [21, 22]. The chronic treatment of duloxetine reversed cognitive dysfunction in stressed mice [23]. Duloxetine has a protective effect on the memory impairment effect of methamphetamine [18]. It is not known that acute duloxetine use has desirable effectiveness following acute exposure to MDMA [19].

The MDMA is a synthetic illicit drug that can mainly damage the brain [24]. The mechanisms 
of the duloxetine have been demonstrated in preclinical and clinical trial studies [17-19, 25]; however, there is no available evidence about duloxetine effects on the MDMA treatment in one week.

\section{Objectives}

This study aimed to investigate the effect of duloxetine treatment following MDMA administration on anxiety, cognition, and memory in male rats.

\section{Materials and Methods}

A total of 50 male adult Wistar rats weighing 260$300 \mathrm{~g}$ were used in this study (Hamadan University of Medical Sciences, Hamadan, Iran). All animals were kept under standard conditions $\left(22 \pm 2^{\circ} \mathrm{C}\right.$ under 12 hours light/12 hours dark cycle) with free access to food and water. The investigations were conducted following the Guide for Care and Animal Rights Protection Act that was published by the national institutes of health (Publication No. 85-23, 1985).

\section{Drug and experimental groups}

The MDMA was obtained from the Drug Control Headquarters of the Police, Iran. The purity and quality of the MDMA have been proved in previous studies [26, 27]. Following that MDMA and Duloxetine (Darou PakhshPharmaceutical Co., Iran) were dissolved in physiological saline $(9 \% \mathrm{NaCl})$ and intraperitoneally injected (10 $\mathrm{ml} / \mathrm{k}$ ) to the treatment groups in accordance with guidelines reported by previously conducted studies $[17,28,29]$. The animals were randomly divided into five groups of eight rats per group. The control group did not receive any treatment, and the sham received saline $(10 \mathrm{ml} / \mathrm{kg}$; i.p.); moreover, the ecstasy (Ext) group received (10 $\mathrm{ml} / \mathrm{kg}$ ) MDMA every other day, and the Dlx group treated with duloxetine every other day. The last group (Dlx +Ext group) received duloxetine and MDMA for 4 days (duloxetine every other day).

\section{Elevated plus maze test}

The anxiety behavior was measured by the elevated plus maze test (EPM) apparatus. The black wooden maze has two enclosed arms $(10 \times 40 \times 50 \mathrm{~cm})$ and double opened arms $(10 \times 50$ $\mathrm{cm}$ ), and the elevated maze has a $50-\mathrm{cm}$ height above the ground. A digital camera was utilized for $10 \mathrm{~min}$ to record the time spent on the open arms, time spent on the closed arms, number of entrances into the open arms, and number of entrances into the closed arms.
New object recognition test

The apparatus of novel object recognition (NOR) is made of a wooden open box $(35 \times 43 \times 40 \mathrm{~cm})$. The habituation phase was performed in an empty box without an object for $5 \mathrm{~min}$. The training session was performed two hours later with two similar objects for $5 \mathrm{~min}$. Similarly, the symmetrical objects two hours later were faced with each other to the floor of the box. Exploratory behavior was defined as the animal sniffing or placing less than $2 \mathrm{~cm}$ from the objects. The test session was given $24 \mathrm{~h}$ after the training trial. A novel object in the test trial was exchanged by one of the objects. The discrimination index (DI) was defined as the difference in time of exploration for the novel and familiar divide by the total time $[22,30]$.

\section{Passive Avoidance Learning test}

The apparatus is the same as that in our studies [31, 32]. The transparent plastic apparatus has a light part $(20 \times 20 \times 30 \mathrm{~cm})$ and a dark part $(20 \times 20 \times 30$ $\mathrm{cm})$. The guillotine's opening walls $(6 \times 8 \mathrm{~cm})$ separated light and dark chambers. The floor of the dark compartment consisted of rods (stainless steel, $3 \mathrm{~mm}$ diameter) linked to a shock generator $(0.4$ $\mathrm{mA}, 50 \mathrm{~Hz}$ for $1.5 \mathrm{~s}$ ).

\section{Training}

The training trials were conducted following those in a previously conducted study [33]. The distance travel and escape latency (time to reach the platform) was measured for $60 \mathrm{sec}$. Each rat received four trials with eight blocks by a $60-\mathrm{min}$ interval resting time. After each trial, the rats were dried with a towel and placed in a home cage near heating.

\section{Retention test}

The rats were tested $24 \mathrm{~h}$ after acquisition trials. The time latency during the test was considered STLr. Moreover, the time of the black part staying was recorded as TDC for $5 \mathrm{~min}$.

\section{Morris water maze test}

The Morris water maze (MWM) test evaluated the hippocampal spatial learning and memory $(155 \times 60$ $\mathrm{cm}$ in diameter and height). The pool has four quadrants and a video-computer tracking system recorded the rat swimming for learning trials and tests.

\section{Training}

The training trials were performed following those in a previously conducted study [23]. The distance travel and escape latency (time to reach the platform) was measured for $60 \mathrm{sec}$. Each rat 
received four trials with eight blocks by a 60-min interval resting time. The soft towel and heating were used to dry animals after each trial.

\section{Retention test}

The retention test was performed $24 \mathrm{~h}$ after the learning trials. The platform was removed at the target quadrant for the probe test. The rats had to swim for $90 \mathrm{sec}$ and the time spent on the target quadrant was recorded using a video-tracking system for $60 \mathrm{sec}$.

\section{Results}

Effect of MDMA and Duloxetine on Elevated Plus Maze

The results of one-way ANOVA showed a significant difference among the groups in terms of the time spent on the open arms $(F[4,32]=22.356$, $\mathrm{P}<0.001$, Figure 1A). Moreover, the Ext group spent more time on the open arms, compared to the control $(\mathrm{P}<0.001)$, sham $(\mathrm{P}<0.01)$, Dlx $(\mathrm{P}<0.001)$, and Dlx+MDMA $(\mathrm{P}<0.001)$ groups. On the other hand, the Dlx group spent less time on the open arms, compared to the control and sham groups
$(\mathrm{P}<0.001$ and $\mathrm{P}<0.01$, respectively). Furthermore, the Dlx + MDMA-treated animals spent less time on the open arms, compared to the sham and control animals $(\mathrm{P}<0.05)$.

The findings obtained by one-way ANOVA also revealed a significant difference regarding the time spent on the closed arms (F $[4,32]=46.810$, $\mathrm{P}<0.001)$. Moreover, the MDMA decreased the time spent on the closed arms in Ext rats, compared to the control, sham, Dlx, and Dlx+MDMA groups $(\mathrm{P}<0.001)$. It is worth noting that there were no other significant differences among the groups (Figure 1B).

Effect of MDMA and Duloxetine on Novel Object Recognition Test

The results of analysis by one-way ANOVA indicated a significant difference among experimental groups in terms of DI (F [4,32] $=3.864, \mathrm{P}<0.01$, Figure 2). The DI of rats receiving MDMA was significantly less than that in the control and sham groups $(\mathrm{P}<0.01)$. There was no significant difference among control, sham, Dlx, and Dlx+MDMA groups in this regard.
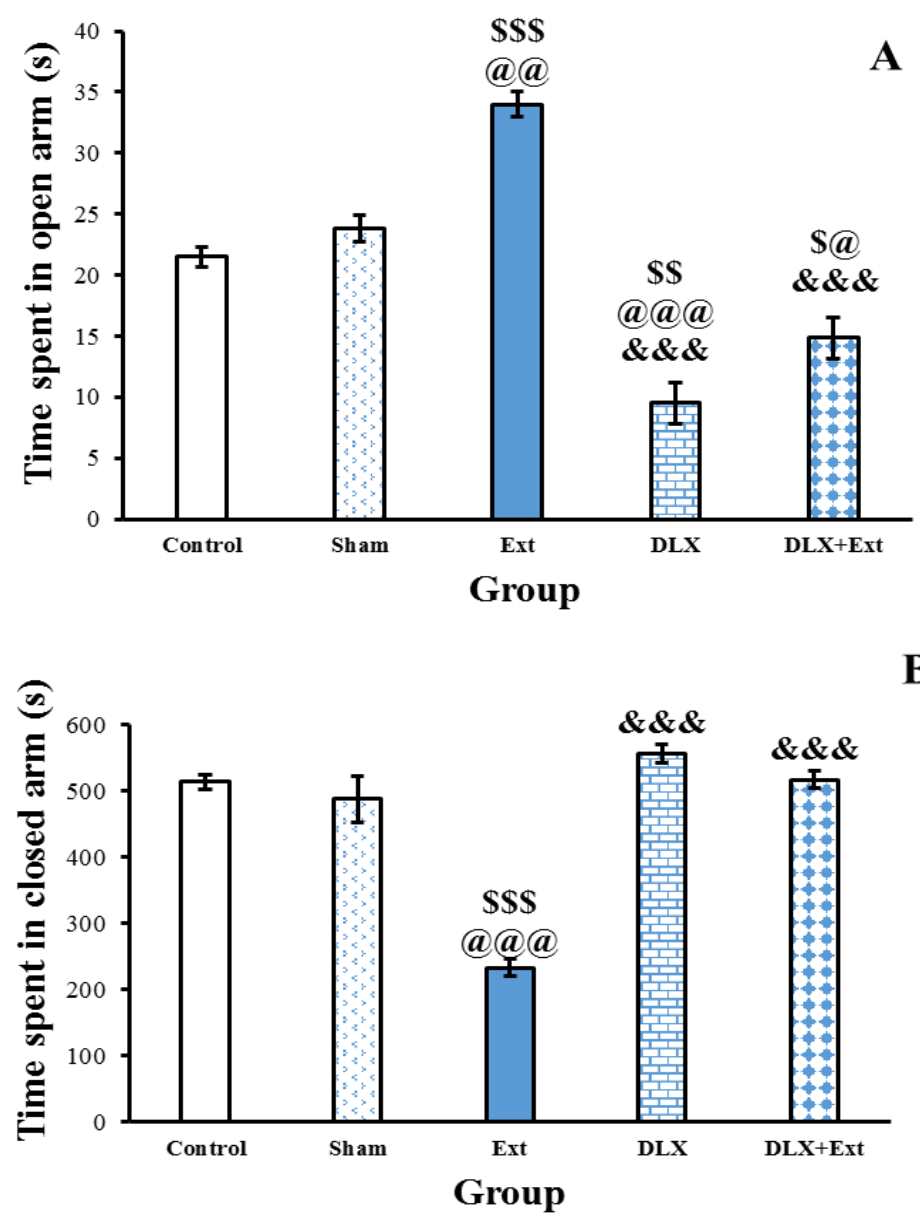

Figure 1. Effects of MDMA and duloxetine treatment on the elevated plus maze. Time spent on the open arms (A) and time spent on the closed arms $(B)$ in the elevated plus maze test. Data are shown as mean \pm SEM. \$\$: $P<0.001, \$ \$: P<0.01$ and $\$$ : $P<0.05$, compared to the control group. @@@: $P<0.001$, @@: $P<0.01$, and @: $P<0.05$, compared to the sham group. \&\&\&: $P<0.001$, compared to the MDMA group. 


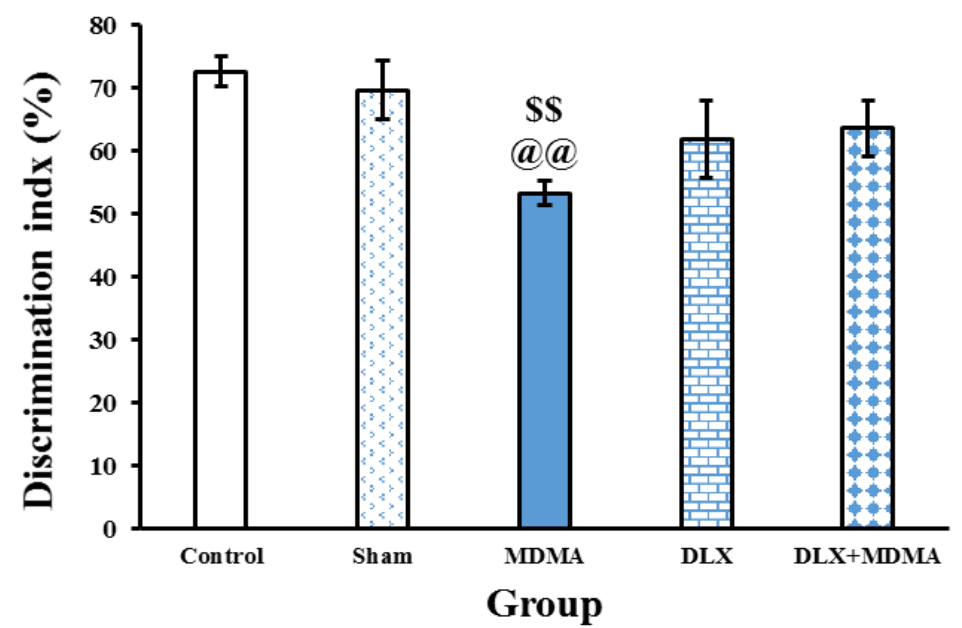

Figure 2. Effects of MDMA and duloxetine treatment on the discrimination index in the novel object recognition test. Data are shown as mean \pm SEM. \$ $\$$ : $<0.01$, compared to the control group, and @@: $\mathrm{P}<0.01$, compared to the sham group

Effect of MDMA and Duloxetine on Passive Avoidance Learning

A significant difference was observed among the groups regarding STLr by one-way ANOVA (F [4, $31]=1.25, \mathrm{P}<0.01)$. Furthermore, the Tukey posttest showed that the STLr of the MDMA group was less than that of the control, sham, and Dlx groups $(\mathrm{P}<0.01, \quad \mathrm{P}<0.01$, and $\mathrm{P}<0.05$, Figure $1 \mathrm{~A})$. $\mathrm{A}$ noteworthy difference in terms of TDC has been revealed among the groups by ANOVA (F [4, 30] $=13.85, \quad \mathrm{P}<0.001)$. Tukey's posttest analysis indicated that TDC in the MDMA group was significantly more than that in the control, sham, Dlx, and Dlx + MDMA groups $(\mathrm{P}<0.01)$. There were no differences among the control, sham, Dlx, and Dlx + MDMA groups in terms of STLr or TDC (Figure 3B).
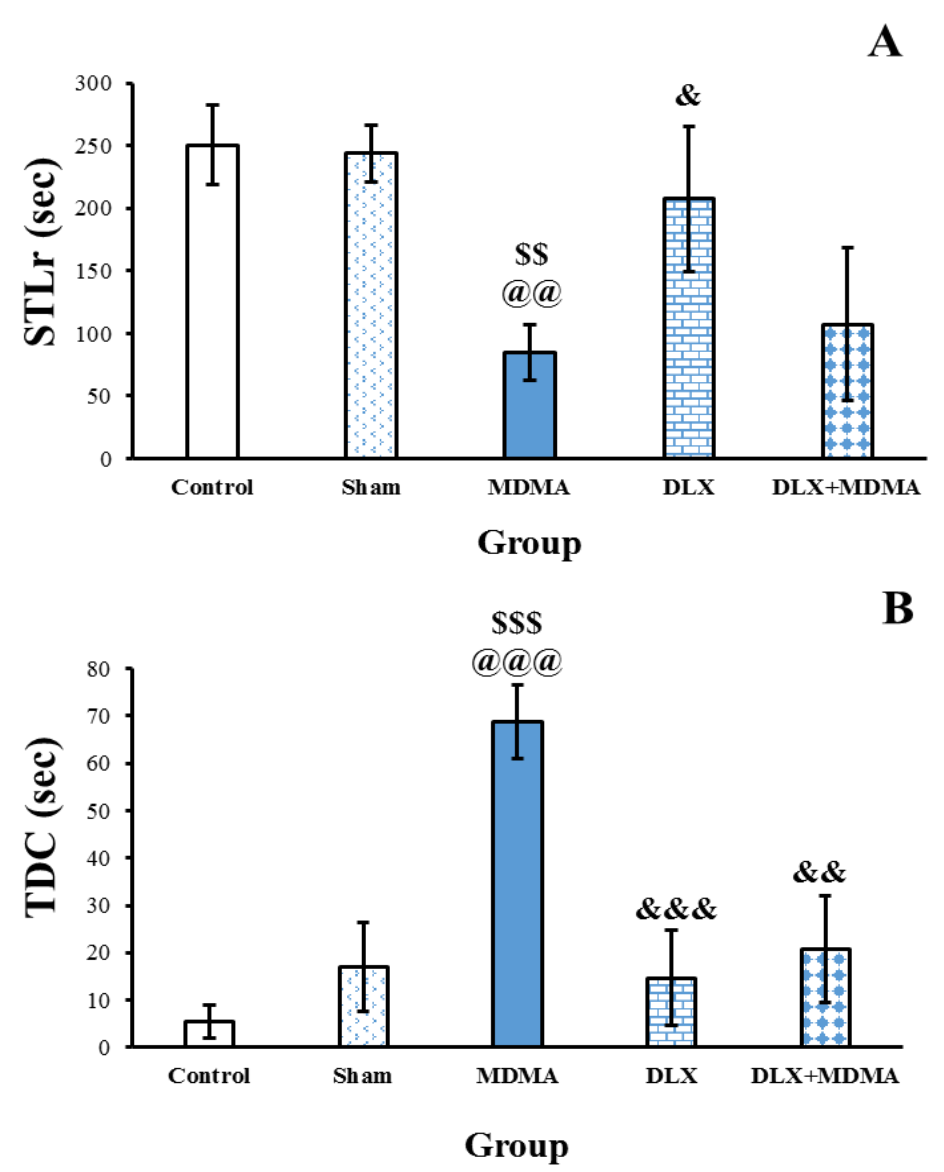

Figure 3. Effects of MDMA and duloxetine treatment on the STLr (A) and TDC (B) in the passive avoidance test. Data are shown as mean \pm SEM. $\$ \$ \$: \mathrm{P}<0.001$, compared to the control group, @@ @: $\mathrm{P}<0.001$, compared to the sham group, \&\&\&: $\mathrm{P}<0.001$, compared to the MDMA group 
Effect of MDMA and Duloxetine on Morris Water Maze

A significant difference was observed among the groups in terms of escape latency by two-way ANOVA analysis $(\mathrm{F}[4,116]=67.656, \mathrm{P}<0.001)$, time $(\mathrm{F}[3,116]=43.105, \mathrm{P}<0.001)$; however, there was no difference among the experimental groups regarding interaction $(\mathrm{F}[12,116]=1.06$, $\mathrm{P}=0.398>0.05)$ (Figure 4A).

The escape latency of the Ext rats was more than that of the control group at first, second, third, and fourth trials of learning $(\mathrm{P}<0.001, \mathrm{P}<0.001$, $\mathrm{P}<0.001$, and $\mathrm{P}<0.001$, respectively). The Dlxtreated rats had a lower time of escape latency, compared to the MDMA group at first, second, third, and fourth trials $(\mathrm{P}<0.05, \mathrm{P}<0.01, \mathrm{P}<0.001$, and $\mathrm{P}<0.001$, respectively).
The Dlx+MDMA group obtained a higher time of escape latency than the control in first, second, third, and fourth trials $(\mathrm{P}<0.05, \mathrm{P}<0.01, \mathrm{P}<0.001$, and $\mathrm{P}<0.001$, respectively). Furthermore, the escape latency of the Dlx+MDMA group was more than that of the sham group in second, third, and fourth trials $(\mathrm{P}<0.001)$; however, it was lower than that in the Ext group in the third $(\mathrm{P}<0.05)$ and fourth $(\mathrm{P}<0.001)$ trials. There was no difference among the experimental groups in terms of the treatment and time interaction.

The two-way ANOVA indicated a significant difference among the groups in terms of distance travel at treatment $(\mathrm{F}[4,116]=125.57, \mathrm{P}<0.001)$ and time $(\mathrm{F}[3,116]=13.085, \mathrm{P}<0.001)$, not their interaction $(\mathrm{F}[12,116]=1.06, \mathrm{P}=0.398>0.0)$ (Figure 4B). The Ext-treated rats obtained more distance

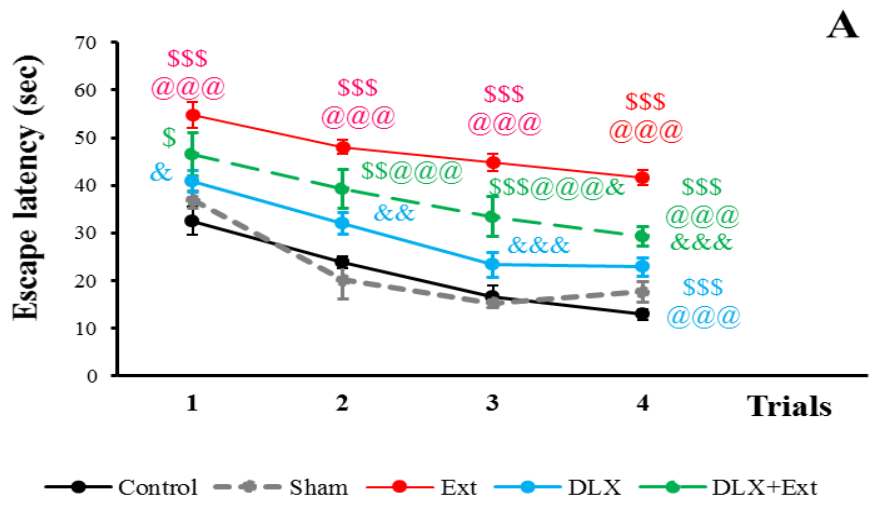

A
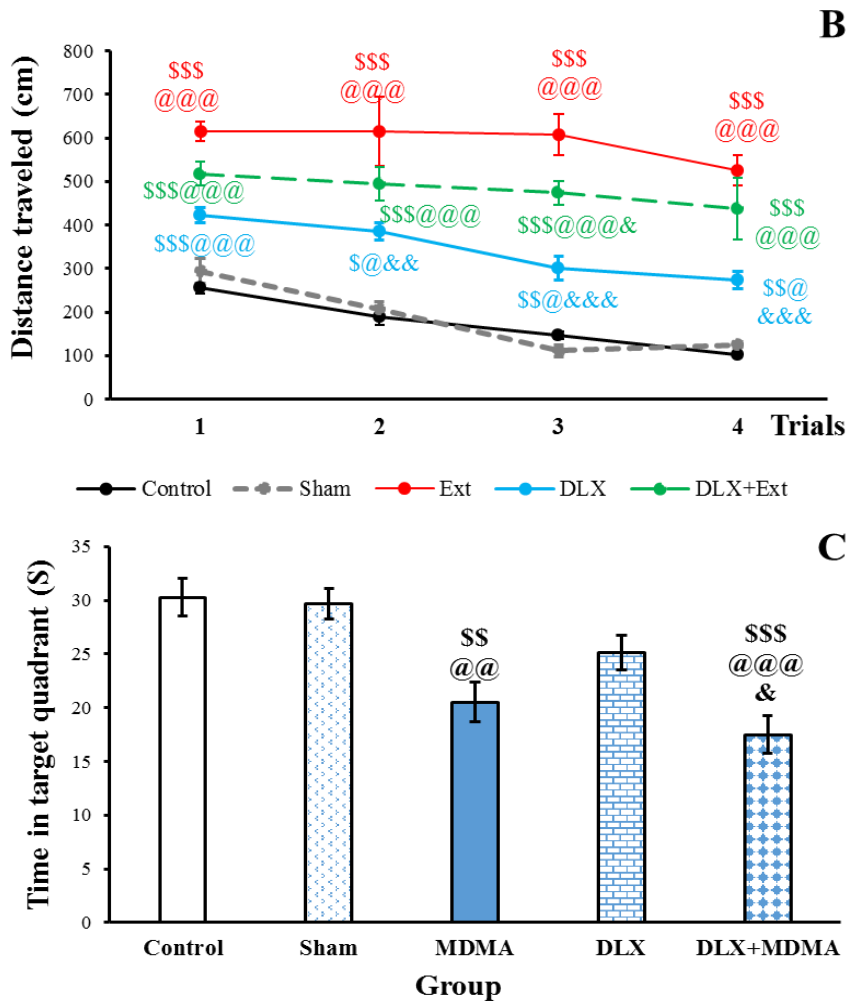

Figure 4. Effects of MDMA and duloxetine treatment on the escape latency (A), distanced travel (B), and time spent on the target quadrant (C) in the Morris water maze test. Data are shown as mean \pm SEM. $\$ \$$ : $P<0.001, \$ \$: P<0.01$, and $\$: P<0.05$, compared to the control group. @@@: $P<0.001$, $@ @: P<0.01$, and @: $\mathrm{P}<0.05$, compared to the sham group. \&\&\&: $\mathrm{P}<0.001, \& \&: \mathrm{P}<0.001$, and $\&: \mathrm{P}<0.05$, compared to the MDMA group. 
travel, compared to the control and sham groups in first, second, third, and fourth trials $(\mathrm{P}<0.001)$. Furthermore, the distance travel of the Dlx group was more than that of the control and sham groups in first $(\mathrm{P}<0.001, \quad \mathrm{P}<0.01)$, second $(\mathrm{P}<0.05$, $\mathrm{P}<0.05)$, third $(\mathrm{P}<0.01, \quad \mathrm{P}<0.05)$, and fourth $(\mathrm{P}<0.01, \mathrm{P}<0.05)$ trials. The distance travel of the Dlx group was more than that in the second $(\mathrm{P}<0.05)$, third $(\mathrm{P}<0.001)$, and fourth $(\mathrm{P}<0.001)$ trials. The Dlx + MDMA group displayed more distance travel, compared to the control and sham groups in first, second, third, and fourth $(\mathrm{P}<0.001$, $\mathrm{P}<0.001, \mathrm{P}<0.001, \mathrm{P}<0.001)$ trials.

According to the results of one-way ANOVA, a significant difference was observed among the groups in terms of time spent on the target quadrant (Figure 4C). Furthermore, the MDMA rats spent less time on the target quadrant, compared to the control and shame groups $(\mathrm{P}<0.01, \mathrm{P}<0.01)$. Additionally, the Dlx + MDMA group obtained lower time, compared to the control $(\mathrm{P}<0.001)$, sham $(\mathrm{P}<0.001)$, and Ext $(\mathrm{P}<0.05)$ groups. There was no significant difference among control, sham, and Dlx rats in this regard.

\section{Discussion}

The present study investigated the effects of duloxetine and MDMA on anxiety, cognition, and memory. The administration of duloxetine into MDMA-treated rats attenuated the anxiolytic effect of MDMA and memory impairment followed by cognition and reacquisition improvement. The duloxetine can be effective against MDMA-induced cognitive disturbance and memory impairment. Furthermore, duloxetine can attenuate the anxiolytic response of MDMA in rats.

The MDMA administration into rats impaired cognition the same as reacquisition memory in passive avoidance learning (PAL) tasks. This result is in line with the findings of the previous studies in which MDMA induced cognition deficit and memory impairment in rodents [8, 9, 18, 29]. Furthermore, MDMA reduces the serotonin content of the brain, as well as the density of neurons and astrocytes in the hippocampus [34]. The harm effect of MDMA is significant in the brain area, which is involved in learning and memory [24]. The neurodegenerative effect of MDMA resulted in cognition deficit and memory impairment in rats. However, the current study did not evaluate the number of neurons in the hippocampus and cortex.

This study showed a decrease in the time spent on the closed arm and an increase in the time spent on the open arm in rats after MDMA treatment, which indicates an anxiolytic-like effect of MDMA in the
EPM test. The results of our study are consistent with the findings of other studies conducted on the animals $[10,11]$ and reported the anxiolytic-like effect of MDMA at a dose of $10 \mathrm{mg} / \mathrm{kg}$ [35]. The other researches showed an anxiogenic-like effect of MDMA at different doses [12, 36].

Another finding of the current study showed that duloxetine could reduce the anxiolytic effect of MDMA. It is demonstrated that duloxetine can improve cognition, anxiety, and depression-like behaviors induced by Methamphetamine [18]. Duloxetine has a neuroprotective role against the neurodegeneration effect of drug abuse [17]. Treatment with duloxetine improved cognition in NOR, learning in MWM, and memory in PAL tasks. These results indicate that duloxetine can reduce the memory impairment effect of MDMA. Previous studies have reported the protective effect of duloxetine on the memory impairment effect of methamphetamine [18].

The mechanisms of MDMA and duloxetine influence on anxiety, cognition, and memory are complex. The MDMA is a synthetic abused drug and significantly harms the brain [24]; moreover, it is a neural stimulant that induces a greater release of serotonin followed by a lesser release of dopamine and norepinephrine into the synaptic cleft $[14,24$, 37]. Duloxetine is an antidepressant, which is used for the treatment of anxiety and major depressive disorder [38, 39]. The serotonin reuptake and norepinephrine reuptake inhibitor duloxetine inhibit MDMA effects [14] and decrease the psychotropic responses to MDMA [16]. On the other hand, MDMA induces serotonergic dysfunction [5] through mitochondrial dysfunction in brain structures that are involved in learning and memory $[3,8,9]$. The other findings suggest that duloxetine can protect the brain against drug abuse, such as methamphetamine, possibly via Cyclic AMP response element-binding and brain-derived neurotrophic factor proteins signaling pathway [18]. In addition, duloxetine, possibly modulates cyclic AMP response element-binding and brain-derived neurotrophic factor signaling pathway [17]; furthermore, it can modulate drug abuse induced inflammation [40] and oxidative stress [17, 41].

The current study showed that treatment with duloxetine without MDMA had no effects on the cognition and memory; however, it increased anxiety behavior. This finding is in line with the results of previous studies that reported no obvious effect of acute treatment on cognition, memory acquisition, or consolidation in rodents [25, 42]. Nevertheless, the chronic treatment of duloxetine has cognition related benefits in depressed patients [19]. Duloxetine treatment showed anxiolytic or 
lack of changes in anxiety effect followed by chronic treatment in rodents $[18,42]$. In the present study, the anxiogenic effect of the produced duloxetine followed acute treatments in rats. Duloxetine as an antidepressant compound induced anxiogenic behavior in the experimental model of anxiety in mice [21, 22]. Chronic treatment is necessary for the anxiolytic-like response of duloxetine [21, 22].

\section{Conclusions}

The present study showed that MDMA administration impaired cognition, avoidance, and spatial memory and induced the anxiolytic-like behavior in the EPM test. Furthermore, duloxetine acute treatment without MDMA induced anxiety and did not affect cognition and memory. Following that, duloxetine administration attenuated the MDMA-induced spatial and avoidance memory impairment. Moreover, duloxetine significantly improved cognition following MDMA treatment. Therefore, duloxetine may be useful to improve the harm effect of MDMA on cognition, learning, and memory. Further studies are required to investigate the impact of duloxetine on the treatment of the patients.

\section{Acknowledgments}

The authors express their gratitude to Ali Nikkhah and Ghazal Yaghootdoost for their contribution to the animal treatment period.

\section{Authors' contributions}

Study design, data statistical analysis, writing, drafting, and revision of the manuscript for content: Siamak Shahidi and Nasrin Hashemi-Firouzi; Sara Soleimani Asl was provided the materials and technical services. Siamak Shahidi supervised this study.

\section{Funding/Support}

This study was supported financially by the Hamadan University of Medical Sciences, Hamadan, Iran (Grant number: 9312186755).

\section{Conflicts of Interest}

The authors declare that they have no conflict of interest.

\section{References}

1. Costa G, Morelli M, Simola N. Repeated administration of 3,4-methylenedioxymethamphetamine (MDMA) elevates the levels of neuronal nitric oxide synthase in the nigrostriatal system: possible relevance to neurotoxicity. Neurotoxicity Research. 2018; 34(4):763-8. [DOI:10.1007/s12640-0189892-4] [PMID]

2. Green AR, Sanchez V, O'Shea E, Saadat KS, Elliott JM, Colado Ml. Effect of ambient temperature and a prior neurotoxic dose of 3,4-methylenedioxymethamphetamine (MDMA) on the hyperthermic response of rats to a single or repeated ('binge' ingestion) low dose of MDMA. Psychopharmacology. 2004; 173(3-4):264-9. [DOI:10.1007/ s00213-003-1725-2] [PMID]

3. Farre M, Tomillero A, Perez-Mana C, Yubero S, Papaseit E, Roset PN, et al. Human pharmacology of 3,4methylenedioxymethamphetamine (MDMA, ecstasy) after repeated doses taken $4 \mathrm{~h}$ apart Human pharmacology of
MDMA after repeated doses taken $4 \mathrm{~h}$ apart. European Neuropsychopharmacology. 2015; 25(10):1637-49. [DOI:10.1016/j.euroneuro.2015.05.007] [PMID]

4. Peiro AM, Farre M, Roset PN, Carbo M, Pujadas $M$, Torrens $M$, et al. Human pharmacology of 3,4-methylenedioxymethamphetamine (MDMA, ecstasy) after repeated doses taken $2 \mathrm{~h}$ apart. Psychopharmacology. 2013. 225(4):883-93. [DOI:10.1007/s00213-012-2894-7] [PMID]

5. Biezonski DK, Meyer JS. The nature of 3, 4methylenedioxymethamphetamine (MDMA)-induced serotonergic dysfunction: evidence for and against the neurodegeneration hypothesis. Current Neuropharmacology. 2011; 9(1):84-90. [DOI:10.2174/15701591179 5017146] [PMID] [PMCID]

6. Yubero-Lahoz S, Pardo R, Farre M, O'Mahony B, Torrens M, Mustata $C$, et al. Sex differences in 3,4-methylenedioxymethamphetamine (MDMA; ecstasy)-induced cytochrome P450 2D6 inhibition in humans. Clinical Pharmacokinetics. 2011; 50(5):319-29. [DOI:10.2165/11584550-00000000000000] [PMID]

7. Gharebaghi A, Amiri I, Salehi I, Shahidi S, Komaki A, Mehdizadeh $M$, et al. Treadmill exercise attenuates 3,4methylenedioxymethamphetamine-induced memory impairment through a decrease apoptosis in male rat hippocampus. Journal of Neuroscience Research. 2017; 95(12):2448-55. [DOI:10.1002/jnr.24078] [PMID]

8. Taghizadeh G, Pourahmad J, Mehdizadeh H, Foroumadi A Torkaman-Boutorabi A, Hassani S, et al. Protective effects of physical exercise on MDMA-induced cognitive and mitochondrial impairment. Free Radical Biology \& Medicine. 2016; 99:11-9. [DOI:10.1016/j.freeradbiomed. 2016.07.018] [PMID]

9. Taghizadeh G, Mehdizadeh H, Pourahmad J, Foroumadi A, Hassani S, Halvaei Khankahdani Z, et al. Bucladesine attenuates spatial learning and hippocampal mitochondrial impairments induced by 3, 4-methylenedioxymethamphetamine (MDMA). Neurotoxicity Research. 2020; 38(1):38-49. [DOI:10.1007/s12640-020-00183-3] [PMID]

10. Majumder I, White JM, Irvine RJ. Antidepressant-like effects of 3,4-methylenedioxymethamphetamine in an animal model of depression. Behavioural Pharmacology. 2011; 22(8):758-65. [DOI:10.1097/FBP.0b013e32834d0f05] [PMID]

11. Ponzoni L, Sala M, Braida D. Ritanserin-sensitive receptors modulate the prosocial and the anxiolytic effect of MDMA derivatives, $\mathrm{DOB}$ and $\mathrm{PMA}$, in zebrafish. Behavioural Brain Research. 2016; 314:181-9. [DOI:10.1016/j.bbr.2016.08.009] [PMID]

12. Ferraz-de-Paula V, Stankevicius D, Ribeiro A, Pinheiro ML, Rodrigues-Costa EC, Florio JC, et al. Differential behavioral outcomes of 3,4-methylenedioxymethamphetamine (MDMAecstasy) in anxiety-like responses in mice. Brazilian Journal of Medical and Biological Research. 2011; 44(5):428-37. [DOI:10.1590/S0100-879X2011007500046] [PMID]

13. Yubero-Lahoz $S$, Ayestas MA Jr, Blough BE, Partilla JS, Rothman RB, de la Torre $\mathrm{R}$, et al. Effects of MDMA and related analogs on plasma 5-HT: relevance to 5-HT transporters in blood and brain. European Journal of Pharmacology. 2012; 674(2-3):337-44. [DOI:10.1016/j. ejphar.2011.10.033] [PMID] [PMCID]

14. Hysek CM, Brugger R, Simmler LD, Bruggisser M, Donzelli $M$, Grouzmann E, et al. Effects of the alpha(2)-adrenergic agonist clonidine on the pharmacodynamics and pharmacokinetics of 3,4-methylenedioxymethamphetamine in healthy volunteers. The Journal of Pharmacology and Experimental Therapeutics. 2012; 340(2):286-94. [DOI:10.1124/jpet.111.188425] [PMID]

15. Goodwin H, Yiend J, Hirsch CR. Generalized anxiety disorder, worry and attention to threat: a systematic review. Clinical Psychology Review. 2017; 54:107-22. [DOI:10.1016/ j.cpr.2017.03.006] [PMID]

16. Hysek CM, Schmid Y, Simmler LD, Domes G, Heinrichs M, Eisenegger $\mathrm{C}$, et al. MDMA enhances emotional empathy and prosocial behavior. Social Cognitive and Affective 
Neuroscience, 2014; 9(11):1645-52. [DOl:10.1093/scan/ nst161] [PMID] [PMCID]

17. Mohammadi N, Taheri P, Shahmoradi E, Motaghinejad M, Gholami M, Motevalian M. Preventive effects of duloxetine against methamphetamine induced neurodegeneration and motor activity disorder in rat: Possible role of CREB/BDNF signaling pathway. International Journal of Preventive Medicine. 2019; 10:195. [DOI:10.4103/ijpvm.IJPVM_53_18] [PMID] [PMCID]

18. Yasuj SR, Nourhashemi M, Keshavarzi S, Motaghinejad M, Motevalian M. Possible role of cyclic AMP response element binding/brain-derived neurotrophic factor signaling pathway in mediating the pharmacological effects of duloxetine against methamphetamine use-induced cognitive impairment and withdrawal-induced anxiety and depression in rats. Advanced Biomedical Research. 2019; 8:11. [DOI:10.4103/abr.abr_34_18] [PMID] [PMCID]

19. Greer TL, Sunderajan P, Grannemann BD, Kurian BT, Trivedi $\mathrm{MH}$. Does duloxetine improve cognitive function independently of its antidepressant effect in patients with major depressive disorder and subjective reports of cognitive dysfunction? Depression Research and Treatment. 2014; 2014:627863. [DOI:10.1155/2014/627863] [PMID] [PMCID]

20. Refsgaard LK, Haubro K, Pickering DS, Stuart SA, Robinson ES, Andreasen JT. Effects of sertraline, duloxetine, vortioxetine, and idazoxan in the rat affective bias test. Psychopharmacology. 2016; 233(21-22):376370. [DOI:10.1007/s00213-016-4407-6] [PMID]

21. Patel S, Kale PP, Addepalli V, Sarkar A, Savai J. Effect of a combination of duloxetine with hydroxyzine on experimental models of anxiety in mice. Indian Journal of Pharmacology. 2015; 47(2):173-6. [DOI:10.4103/02537613.153424] [PMID] [PMCID]

22. Troelsen K, Nielsen E, Mirza N. Chronic treatment with duloxetine is necessary for an anxiolytic-like response in the mouse zero maze: the role of the serotonin transporter. Psychopharmacology. 2005; 181(4):741-50. [DOI:10.1007/ s00213-005-0032-5] [PMID]

23. Xu H, Zhang Y, Zhang F, Yuan SN, Shao F, Wang W. Effects of duloxetine treatment on cognitive flexibility and BDNF expression in the mPFC of adult male mice exposed to social stress during adolescence. Frontiers in Molecular Neuroscience. 2016; 9:95. [DOI:10.3389/fnmol.2016. 00095] [PMID] [PMCID]

24. Creagh S, Warden D, Latif M, Paydar A. The new classes of synthetic illicit drugs can significantly harm the brain: a neuro imaging perspective with full review of MRI findings. Clinical Radiology \& Imaging Journal. 2018; 2(1):000116. [PMID] [PMCID]

25. Pereira P, Gianesini J, da Silva Barbosa C, Cassol GF, Von Borowski RG, Kahl VF, et al. Neurobehavioral and genotoxic parameters of duloxetine in mice using the inhibitory avoidance task and comet assay as experimental models. Pharmacological Research. 2009; 59(1):57-61. [DOI:10.1016/j.phrs.2008.09.014] [PMID]

26. Asi S, Farhadi H, Naghdi N, Choopani S, SamzadehKermani A, Mehdizadeh M. Non-acute effects of different doses of 3, 4-methylenedioxymethamphetamine on spatial memory in the Morris water maze in Sprague-Dawley male rats. Neural Regeneration Research. 2011; 6(22):1715-9. [DOI:10.3969/j.issn.1673-5374.2011.22.006]

27. Sajadi A, Amiri I, Gharebaghi A, Komaki A, Asadbeigi M, Shahidi S, et al. Treadmill exercise alters ecstasy-induced long-term potentiation disruption in the hippocampus of male rats. Metabolic Brain Disease. 2017; 32(5):1603-7. [DOI:10.1007/s11011-017-0046-9] [PMID]

28. Mehdizadeh M, Dabaghian F, Nejhadi A, Fallah-huseini H, Choopani S, Shekarriz N, et al. Zingiber officinale alters 3, 4-methylenedioxymethamphetamine-induced neurotoxicity in rat brain. Cell Journal. 2012; 14(3):177-84. [PMID] [PMCID]
29. Shariati MB, Sohrabi M, Shahidi S, Nikkhah A, Mirzaei F, Medizadeh $M$, et al. Acute effects of ecstasy on memory are more extensive than chronic effects. Basic and Clinical Neuroscience. 2014; 5(3):225-30. [PMID] [PMCID]

30. Hashemi FN, Akhavan M, Komaki A, Shahidi S. Effects of acute administration of Urtica dioica on the novel objectrecognition task in mice. Avicenna Journal of Neuro Psycho Physiology. 2015; 2(3):e34150. [DOl:10.17795/ajnpp34150]

31. Beigi B, Shahidi S, Komaki A, Sarihi A, Hashemi-Firouzi N. Pretraining hippocampal stimulation of melatonin type 2 receptors can improve memory acquisition in rats. International Journal of Neuroscience. 2018; 129(5):492500. [DOI:10.1080/00207454.2018.1545770] [PMID]

32. Hashemi-Firouzi N, Shahidi S, Soleimani-Asl S, Komaki A. 5-Hydroxytryptamine receptor 6 antagonist, SB258585 exerts neuroprotection in a rat model of Streptozotocininduced Alzheimer's disease. Metabolic Brain Disease. 2018; 33(4):1243-53. [DOI:10.1007/s11011-018-0228-0] [PMID]

33. Shahidi S, Motamedi F, Naghdi N. Effect of reversible inactivation of the supramammillary nucleus on spatial learning and memory in rats. Brain Research. 2004; 1026(2):267-74. [DOI:10.1016/j.brainres.2004.08.030] [PMID]

34. Jahanshahi M, Haidari K, Mahaki-Zadeh S, Nikmahzar E, Babakordi F. Effects of repeated administration of 3, 4methylenedioxymethamphetamine (MDMA) on avoidance memory and cell density in rats' hippocampus. Basic and Clinical Neuroscience. 2013; 4(1):57-63. [PMID] [PMCID]

35. Palenicek T, Votava M, Bubenikova V, Horacek J. Increased sensitivity to the acute effects of MDMA ("ecstasy") in female rats. Physiology \& Behavior. 2005; 86(4):546-53. [DOI:10.1016/j.physbeh.2005.08.043] [PMID]

36. Macúchová E, Ševčíková M, Hrebíčková I, Nohejlová K, Šlamberová R. How various drugs affect anxiety-related behavior in male and female rats prenatally exposed to methamphetamine. International Journal of Developmental Neuroscience. 2016; 51:1-11. [DOl:10.1016/j.ijdevneu. 2016.04.001] [PMID]

37. Rizzo FR, Federici M, Mercuri NB. 3, 4Methylenedioxymethamphetamine (MDMA) alters synaptic dopamine release in the dorsal striatum through nicotinic receptors and DAT inhibition. Neuroscience. 2018; 377:6976. [DOI:10.1016/j.neuroscience.2018.02.037] [PMID]

38. Bansal R, Hellerstein DJ, Sawardekar S, O'Neill J, Peterson BS. Effects of the antidepressant medication duloxetine on brain metabolites in persistent depressive disorder: a randomized, controlled trial. PloS One. 2019; 14(7): e0219679. [DOI:10.1371/journal.pone.0219679] [PMID] [PMCID]

39. National Institutes of Health. LiverTox: clinical and research information on drug-induced liver injury. Bethesda (MD): National Institute of Diabetes and Digestive and Kidney Diseases; 2012.

40. Tynan RJ, Weidenhofer J, Hinwood M, Cairns MJ, Day TA, Walker FR. A comparative examination of the antiinflammatory effects of SSRI and SNRI antidepressants on LPS stimulated microglia. Brain, Behavior, and Immunity. 2012; 26(3):469-79. [DOI:10.1016/j.bbi.2011.12.011] [PMID]

41. Akpinar A, Uğuz AC, Nazıroğlu M. Agomelatine and duloxetine synergistically modulates apoptotic pathway by inhibiting oxidative stress triggered intracellular calcium entry in neuronal PC12 cells: role of TRPM2 and voltagegated calcium channels. The Journal of Membrane Biology. 2014; 247(5):451-9. [DOI:10.1007/s00232-0149652-1] [PMID]

42. Kale PP, Addepalli V. Enhancement of nootropic effect of duloxetine and bupropion by caffeine in mice. Indian Journal of Pharmacology. 2015; 47(2):199-201. [DOI:10.4103/0253-7613.153430] [PMID] [PMCID] 